\title{
Generic health literacy measurement instruments for children and adolescents: a systematic review of the literature
}

\author{
Orkan Okan ${ }^{1 *} \mathbb{D}$, Ester Lopes ${ }^{1}$, Torsten Michael Bollweg ${ }^{1}$, Janine Bröder ${ }^{1}$, Melanie Messer ${ }^{2}$, Dirk Bruland ${ }^{1}$, \\ Emma Bond ${ }^{3}$, Graça S. Carvalho ${ }^{4}$, Kristine Sørensen ${ }^{5}$, Luis Saboga-Nunes ${ }^{6}$, Diane Levin-Zamir ${ }^{7,12}$, Diana Sahrai ${ }^{8}$, \\ Uwe H. Bittlingmayer ${ }^{9}$, Jürgen M. Pelikan ${ }^{10}$, Malcolm Thomas $^{11}$, Ullrich Bauer ${ }^{1}$ and Paulo Pinheiro ${ }^{1}$
}

\begin{abstract}
Background: Health literacy is an important health promotion concern and recently children and adolescents have been the focus of increased academic attention. To assess the health literacy of this population, researchers have been focussing on developing instruments to measure their health literacy. Compared to the wider availability of instruments for adults, only a few tools are known for younger age groups. The objective of this study is to systematically review the field of generic child and adolescent health literacy measurement instruments that are currently available.

Method: A systematic literature search was undertaken in five databases (PubMed, CINAHL, PsycNET, ERIC, and FIS) on articles published between January 1990 and July 2015, addressing children and adolescents $\leq 18$ years old. Eligible articles were analysed, data was extracted, and synthesised according to review objectives.

Results: Fifteen generic health literacy measurement instruments for children and adolescents were identified. All, except two, are self-administered instruments. Seven are objective measures (performance-based tests), seven are subjective measures (self-reporting), and one uses a mixed-method measurement. Most instruments applied a broad and multidimensional understanding of health literacy. The instruments were developed in eight different countries, with most tools originating in the United States $(n=6)$. Among the instruments, 31 different components related to health literacy were identified. Accordingly, the studies exhibit a variety of implicit or explicit conceptual and operational definitions, and most instruments have been used in schools and other educational contexts. While the youngest age group studied was 7year-old children within a parent-child study, there is only one instrument specifically designed for primary school children and none for early years.

Conclusions: Despite the reported paucity of health literacy research involving children and adolescents, an unexpected number of health literacy measurement studies in children's populations was found. Most instruments tend to measure their own specific understanding of health literacy and not all provide sufficient conceptual information. To advance health literacy instruments, a much more standardised approach is necessary including improved reporting on the development and validation processes. Further research is required to improve health literacy instruments for children and adolescents and to provide knowledge to inform effective interventions.
\end{abstract}

Keywords: Health literacy, Measurement, Assessment, Instrument, Children, Adolescents, Literature review

\footnotetext{
* Correspondence: orkan.okan@uni-bielefeld.de

${ }^{1}$ Faculty of Educational Science, Centre for Prevention and Intervention in

Childhood and Adolescents (CPI), Bielefeld University, Bielefeld, NRW,

Germany

Full list of author information is available at the end of the article
}

(c) The Author(s). 2018 Open Access This article is distributed under the terms of the Creative Commons Attribution 4.0 International License (http://creativecommons.org/licenses/by/4.0/), which permits unrestricted use, distribution, and reproduction in any medium, provided you give appropriate credit to the original author(s) and the source, provide a link to the Creative Commons license, and indicate if changes were made. The Creative Commons Public Domain Dedication waiver (http://creativecommons.org/publicdomain/zero/1.0/) applies to the data made available in this article, unless otherwise stated. 


\section{Background}

Health literacy is currently experiencing increased attention in contemporary research, practice, and policy [17]. In health promotion, health literacy is understood to be an empowering resource for individuals, related to education and linked to literacy. It comprises the skills, knowledge, and motivation to access, understand, and appraise health-related information in order to apply informed health decisions in everyday life [1]. Although health literacy remains content specific, contextual factors impact on the practice of health literacy as well, and health literacy should ideally improve individual health behaviour [8]. In addition, health literacy is a doublesided concept that encompasses individual capabilities as well as system demands and complexities, which influence health behaviours and health-related interactions $[9,10]$.

Current research links limited health literacy to a lack of health knowledge, poor disease management skills, medication treatment errors, inadequate health communication skills, difficulties in navigating the healthcare system, poor access to healthcare services, increased healthcare costs, and poorer health outcomes [11]. In Europe, the European Health Literacy study (HLS-EU) conducted in eight countries found that an average of $47 \%$ of all respondents had limited health literacy [10]. Most of these studies were conducted among adults, and comparatively, the scientific literature on child and adolescent health literacy lacks evidence. Although health literacy is rooted in school health education aimed at improving children's health literacy [12], children and adolescents have been given little attention in health literacy studies in past decades [13-16]. This contradicts with the importance given to childhood and adolescence for the development of health skills, health-related knowledge, and healthy behaviours and practices [1719].

Many scholars argue, in accordance with findings from developmental research, that effective health literacy development begins in early childhood $[13,20,21]$ and that schools are viewed as major settings for early health literacy promotion [22-24]. Recently, there have been some remarkable efforts towards performing research with younger age groups [14, 25-30]. Interestingly, due to the growing attention paid to children and adolescents for health literacy development, health literacy promotion in early childhood has been exclusively included in a policy brief of the World Health Organization (WHO) on investing in health literacy in the European Region [6] and in their recently published Shanghai declaration on health promotion [7].

To identify the needs of children and adolescents and to address specific target areas for action, validated and reliable measurement instruments to assess health literacy are crucial $[5,26,27]$. Although over a hundred instruments measuring either specific or generic health literacy in adults have been identified in several systematic and/or scoping reviews [4, 31-37], to date there is only one systematic review on child and adolescent measurement tools [38]. This review identified 16 tools comprising both generic and specific health literacy instruments developed between 2007 and 2011 with mixed results suggesting that available tools are not adequately measuring and depicting health literacy. Furthermore, the authors of that review suggest that future research regarding concepts and measurements should shift away from a healthcare perspective to a health promotion and education perspective instead. Another potential criticism arises from the fact that each instrument uses its own specific understanding of health literacy, which makes it difficult to compare results across studies.

This present systematic review, therefore, aims to identify, retrieve, analyse, and assess available generic health literacy measurement instruments for children and adolescents $\leq 18$ years old. To specifically and exclusively focus on generic health literacy tools only, measurement tools for domain-specific health literacies, such as mental health literacy, oral health literacy, eHealth literacy, and media health literacy, were excluded from this study. In this review specific attention will be paid to the following:
a) instrument characteristics;
b) country of origin and setting;
c) target or age group;
d) questionnaire administration mode;
e) participant participation in the development process of the questionnaires;
f) psychometric properties;
g) contextual factors;
h) underlying health literacy models/definitions; and
i) scope of measured components.

This systematic literature review was conducted as part of the MoMChild project (Methods of Measuring Health Literacy in Children), which is part of the German Health Literacy in Childhood and Adolescence Research Consortium (HLCA).

\section{Method}

The research team conducted a systematic review of the literature on health literacy measurement instruments for children and adolescents $\leq 18$ years old. To ensure transparency and completeness of the research and to improve the reporting of this review, the 27-item checklist of the Preferred Reporting Items for Systematic reviews and Meta-Analyses (PRISMA statement) was adopted and included in the supplementary information 
files of this article. The PRISMA flow diagram (see Fig. 1) illustrates the inclusion and exclusion process [39].

\section{Data sources, search strategy, and study selection}

Three researchers (OO, MM, PP) developed the search strategy/method and algorithm. Two researchers (OO, EL) independently searched the databases using identical search algorithms for the respective databases and analysed the data. Three researchers (TMB, MM, JB) checked the initial results, and five researchers $(\mathrm{OO}$, TMB, MM, JB, PP) critically discussed the search outcomes.

\section{Data sources}

The search was performed in five databases: Medline via PubMed, the Cumulative Index to Nursing and Allied Health Literature (CINAHL) via EBSCOhost, the American Psychological Association (APA) PsycNET search platform, the Educational Resources Information Center (ERIC), and the German Fachinformationssystem Bildung (FIS).

\section{Search strategy}

The five abovementioned databases were initially searched from May - July 2015 using a composite search term that comprised a combination of three terms for papers published between January 1990 and July 2015. To combine search terms Boolean operators (AND/OR) were used. Wildcard characters were used in order to cover all spelling variations of the search terms. The first search term was "health literacy", the second

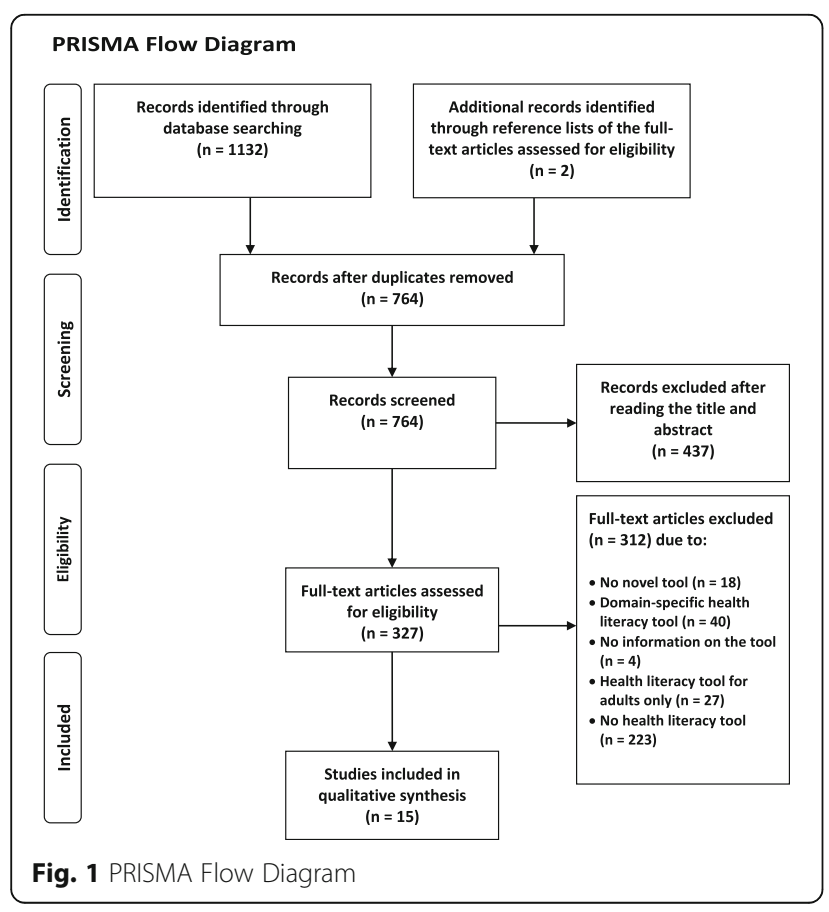

addressed the target population ("child"”, "adolescen", or "youth"), and the third term focused on either one of ten common terms/topics in the context of measurement tools ("measur*", "test"*, "tool"*, "instrument" ${ }^{*}$ ", "questionnaire*", "assessment"”", "screen"”, "survey", "psychometric", and "review"). In the FIS, the search terms "Gesundheitsbildung" and "Gesundheitskompetenz" were used. Additionally, reference lists of included full-text articles were searched manually (OO) for potentially relevant publications. The following algorithm has been used in PubMed, while the search strategy used in PubMed was adapted to the specifications of the other four databases (see Additional files 1 and 2).

((health literacy[Title/Abstract]) AND ((child*[Title/ Abstract]) OR (adolescen*[Title/Abstract]) OR (youth[Title/Abstract])) AND ((measur*[Title/Abstract]) OR (test*[Title/Abstract]) OR (tool*[Title/Abstract]) OR (instrument*[Title/Abstract]) OR (questionnaire*[Title/ Abstract]) OR (assessment*[Title/Abstract]) OR (screen*[Title/Abstract]) OR (survey*[Title/Abstract]) OR (psychometric ${ }^{*}$ [Title/Abstract]) OR (review*[Title/ Abstract])))

\section{Study selection}

For the purposes of this search, the following inclusion criteria were used (see Table 1): (a) time of publication between January 1990 and July 2015 (as the first health literacy tool was introduced in the early 1990s); (b) English or German language; (c) original publication describing the first use of a health literacy instrument; (d) a study population of children and/or adolescents or at least including these; (e) any setting, i.e., healthcare, schools or other; and (f) any country.

\section{Screening, data extraction, and analysis}

Five researchers (OO, EL, TMB, MM, JB) participated in the screening process. Screening took place in two steps: (1) title/abstract screening was performed by two researchers (OO, EL) independently, and (2) full-text analysis of the eligible publications was performed by three researchers (OO, EL, MM). Two researchers (TMB, JB) checked the results independently. To find consensus and validate the findings, expert consultations were performed by approaching the other authors (DB, EB, GSC, KS, LSN, DLZ, DS, UHB, JP, MT, UB, PP). Literature was imported to the reference management software CITAVI 5. The characteristics of the health literacy measurement instruments identified in the relevant publications were analysed and extracted by two researchers independently (OO, EL) based on the objectives of this review. The decision on what data to extract from the articles was based partly on (a) former systematic reviews of health literacy measurement tools [4, 38] and (b) an extensive discussion and consensus among the 
Table 1 Inclusion and exclusion criteria

\begin{tabular}{|c|c|c|}
\hline Criterion & Inclusion & Exclusion \\
\hline Time & January 1990 - July 2015 & Studies before 1990 and after July 2015 \\
\hline Language & English, German & Any other language \\
\hline Type of publication & $\begin{array}{l}\text { Original papers published in } \\
\text { peer-reviewed journals, or reports }\end{array}$ & $\begin{array}{l}\text { Any non-original publication, any editorials, } \\
\text { letters to editors, theses, books }\end{array}$ \\
\hline Focus of study & $\begin{array}{l}\text { Any study reporting on a generic } \\
\text { health literacy instrument, its first-time } \\
\text { use, development or validation process }\end{array}$ & $\begin{array}{l}\text { Any study reporting on a domain-specific } \\
\text { health literacy instrument (i.e. mental health } \\
\text { literacy, media or eHealth literacy), and any } \\
\text { non-health literacy instrument }\end{array}$ \\
\hline Study population & $\begin{array}{l}\text { Articles including children and adolescents } \\
\leq 18 \text { years }\end{array}$ & Any population older $>18$ years \\
\hline Setting & Any setting & $\mathrm{Nil}$ \\
\hline Country & Any country & $\mathrm{Nil}$ \\
\hline
\end{tabular}

authors of this review and with further health literacy experts from the HLCA research consortium. If information on the validity and reliability of instruments was documented within the articles, these data were extracted and analysed as well.

\section{Results}

This review focused exclusively on generic health literacy measures. The search process identified $N=1132$ publications matching the search criteria (PubMed $n=$ 291, CINHAL $n=201$, PsycNET $n=357$, ERIC $n=226$, FIS $n=57$ ). The manual search led to the identification of an additional $n=2$ articles (see Fig. 1: PRISMA flow diagram). After removing duplicates, $n=764$ articles remained, of which a further $n=437$ articles were excluded after screening the titles and abstracts. A total of $n=327$ articles underwent full-text analysis. Finally, all articles not matching the inclusion criteria $(n=312)$ were excluded from qualitative synthesis yielding $N=15$ articles reporting 15 different questionnaires.

\section{Instrument characteristics}

Among the identified instruments (see Table 2), ten instruments are novel instruments that were developed especially either for children and/or adolescents [40-47] or for adult age groups including adolescents 15 years and older $[48,49]$. In relation to the teen version of the Rapid Estimate of Adolescent Literacy in Medicine (REALM-teen) [50], the adolescent version of the Test of Functional Health Literacy in Adults (TOFHLAd) [51], and the Newest Vital Sign (NVS) [52], our review identified child and adolescent adaptations of the most widely used fast-screening instruments in clinical and medical-related adult health literacy research. Another adaptation/validation study conducted in Austria [53] applied the population-based health literacy tool HLSEU-Q47, which was developed for the HLS-EU [10]. This tool, which was originally developed and validated for adults (15 years + ), was specifically validated as a long form of the tool and subsequently adapted as a short form for adolescents. Finally, one of the identified instruments is a shorter form of an already existing health literacy measurement tool for adolescent mothers, but analysis of the longer form of the tool is yet not published [54]. REALM-teen was the first health literacy instrument ever to be applied in a child population during a validation study [50]. The most recent study to use this instrument was conducted with the Maternal Health Literacy (MaHeLi) scale in Uganda in 2015. Questionnaire items are fully provided in seven of the studies [40, $43,47,49,52-54$ ] but are not provided at all in seven other studies [41, 42, 44, 45, 48,50,51]. One study provides only some of the items [46].

\section{Country of origin and setting}

Six of the health literacy measurement instruments were developed or applied in the United States [40, 41, 47, $50-52]$, followed by three from Germany [43, 46, 48] and one each from Greece [42], the United Kingdom (England) [49], Canada [44], China [45], Uganda [54] and Austria [53]. Two articles were published in German $[46,53]$, and the rest were published in English. While one instrument was used in the general population and not in a specific setting [53], nine studies took place in schools or other educational settings [40-46, 48, 52], four in healthcare settings $[47,49,51,54]$, and one in a mixed setting (educational and healthcare) [50].

\section{Target or age group}

The majority of studies (eleven) provided the exact age of the target group, but this was not specified in the other four studies [41, 44-46]. In these studies, the type of school was specified; three of these studies were performed in secondary schools $[41,44,46]$, and one study was performed in both elementary and middle schools [45]. While all instruments have been used in age groups older than 11 years [40-54]; five of these instruments have been used with children 10 years old and younger 


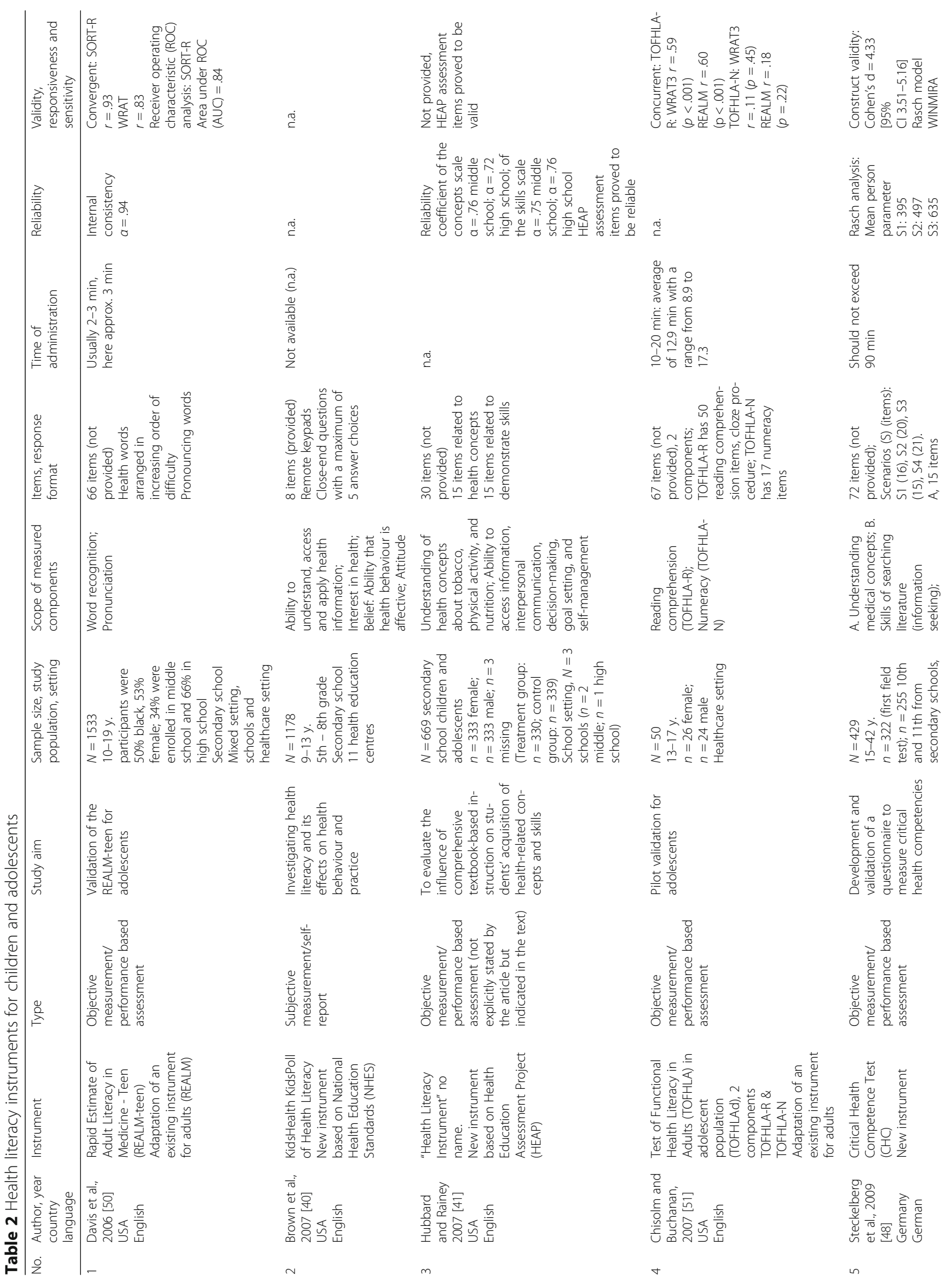




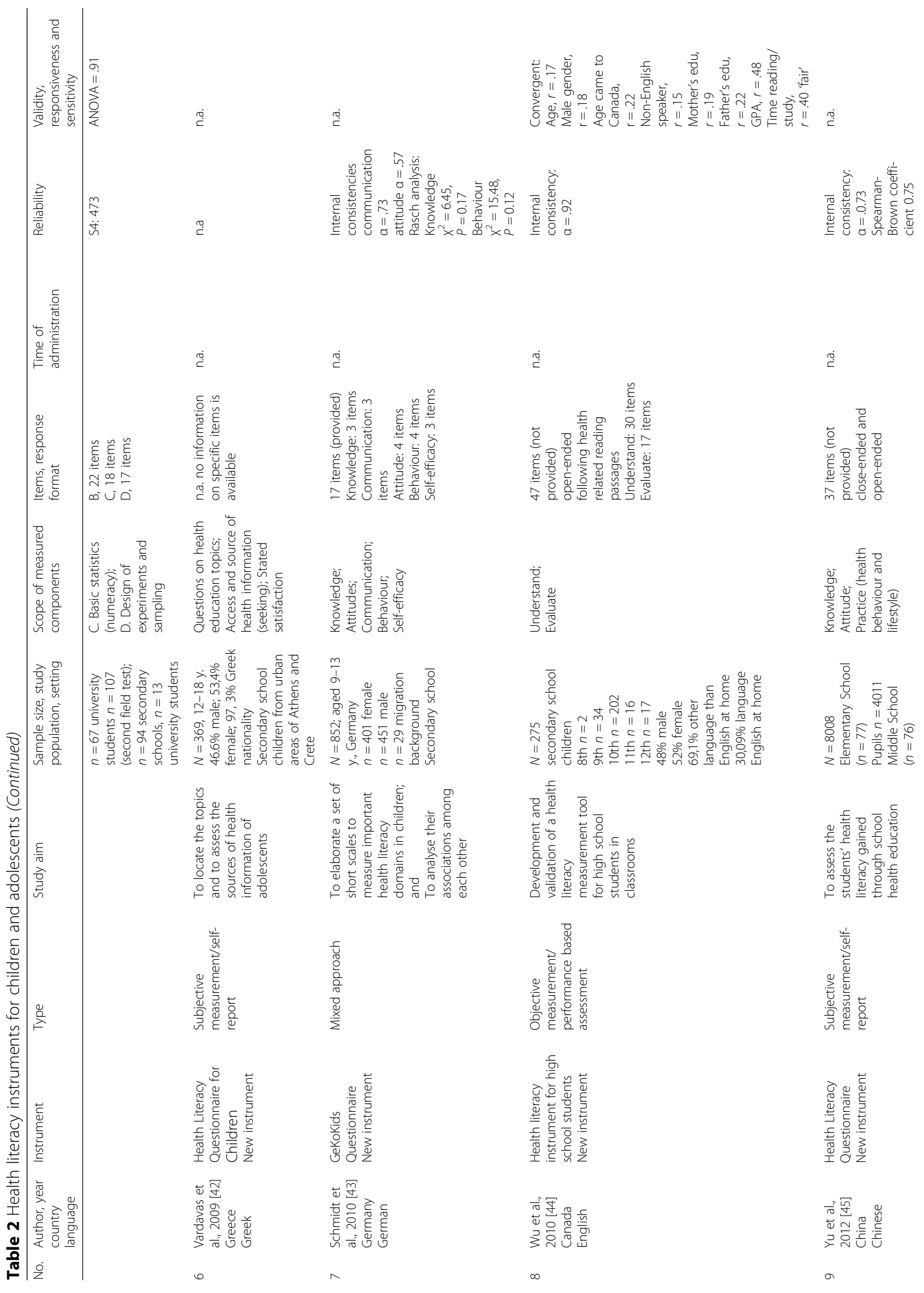




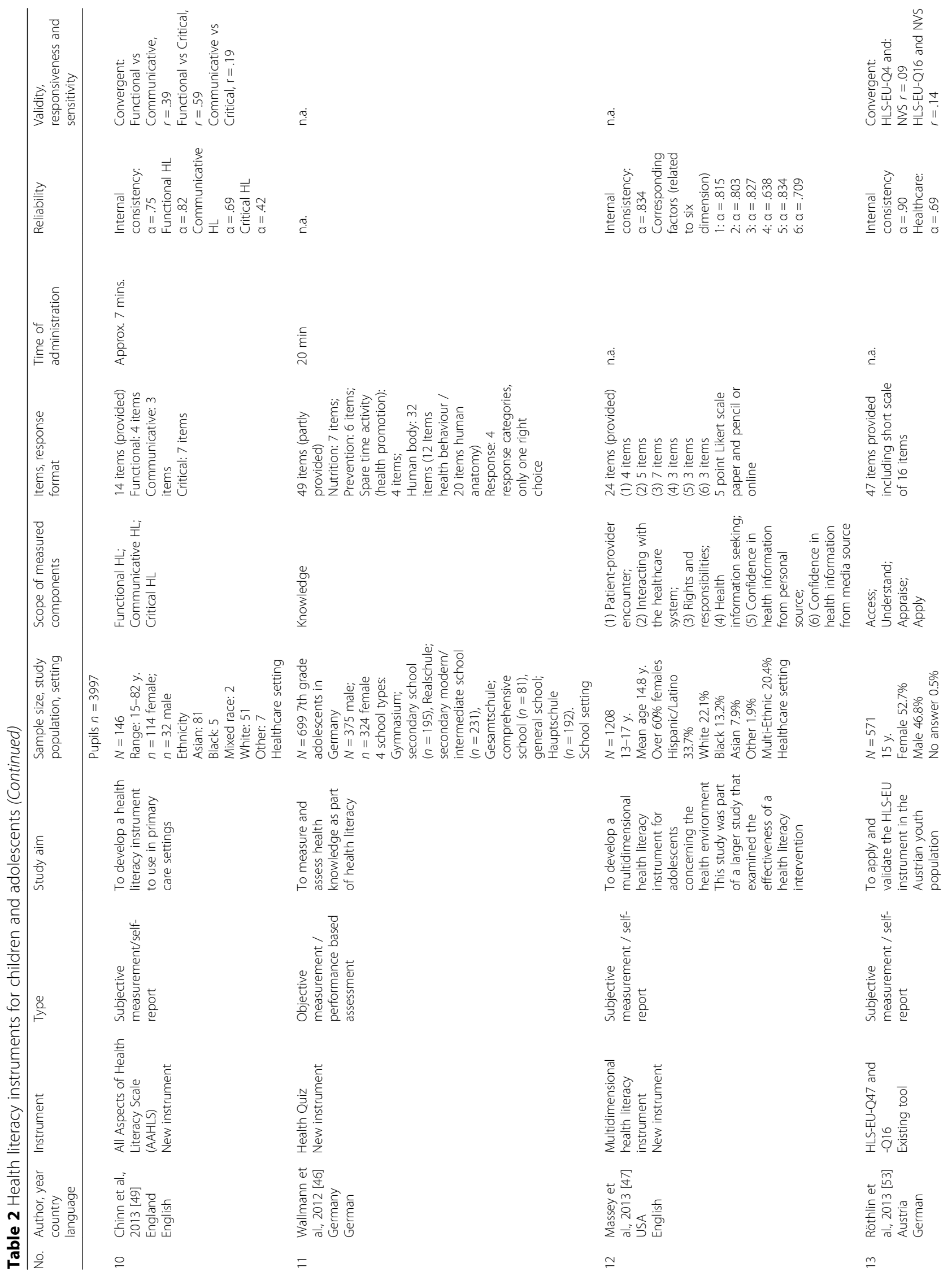




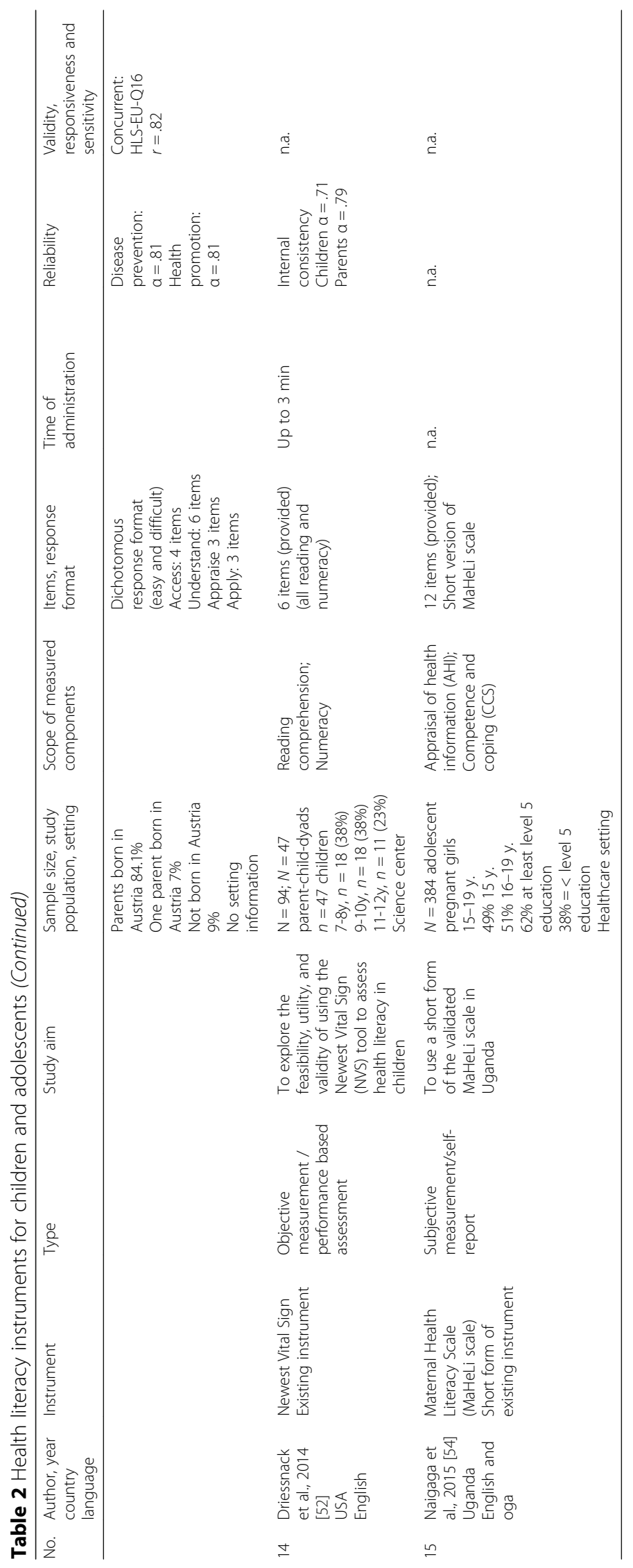


as well $[40,43,45,50,52]$, among which only three were specifically designed for children of this age: 9 to 13 years [40, 43], primary school-aged children [45].

\section{Questionnaire administration mode: Objective and subjective measurement}

The analysis showed that seven health literacy tools were based on subjective measurement using self-reporting questionnaires [40, 42, 45, 47, 49, 53, 54]. Another seven articles reported the use of objective measures assessing the actual performance in given tasks [41, 44, 46, 48, 50-52]. One study adopted a mixed-method approach that combined both test methods [43]. All instruments were self-administered measures, except for two that adopted the use of structured interviews to collect the data $[50,53]$. Four questionnaires were based on the pen-and-paper mode $[46,51,52,54]$ and another study used a computer-based questionnaire [40]. However, for eight questionnaires the specific administration mode (pen-and-paper or digital) was not provided by the authors [41-45, 47-49]; of these studies, one used two booklets given to the participants indicating that penand-paper may have been the mode of administration [44]. Two instruments used a mixture of open-ended and close-ended questions [44, 45], seven used closeended questions only [40, 43, 47, 49, 52-54], and five did not provide sufficient information on the specific question types $[41,42,48,50,51]$.

\section{Participant inclusion in questionnaire development}

Only two articles reported the involvement of participants in the development of the questionnaire by conducting qualitative research in order to derive meaning about health literacy from the target population [47, 49]. Massey et al. [47] conducted 12 focus groups with adolescents 13-17 years old and interviewed eight primary care providers who worked with adolescent populations. Chinn et al. [49] conducted expert consultation and focus groups with health and non-health professionals as well as with patients. However, these authors did not report the specific age of the participants. Cognitive pretesting was conducted by six studies to obtain qualitative feedback by using methods, such as think-aloud techniques or interviews related to question comprehension or feasibility [40, 41, 44, 47-49].

\section{Psychometric properties}

Nearly all the studies reported the psychometric properties of the instruments (see Table 2). The reported reliability differed across measures, with internal consistency ranging from $\alpha=0.42-0.94$. The highest reported rates were $\alpha=0.94$ [50], $\alpha=0.92$ [44], $\alpha=0.90$ [53] and $\alpha=0.83$ [47]. The weakest internal consistency was reported for the attitude scale $\alpha=0.57$ in the
GeKoKids questionnaire [43] and for the critical health literacy scale $\alpha=0.42$ in the AAHLS questionnaire [49].

Reporting on the convergent validity of most instruments was insufficient. For those provided, these data were positive and moderate $(r=0.09-0.93)$. However, concurrent validities were often not tested or not reported. REALM-teen [50] correlated significantly with WRAT $(r=0.83)$ and SORT-R $(r=0.93)$. TOFHLAd [51] was strongly correlated with WRAT3 $(r=0.59)$ and REALM ( $r=0.60)$. HLS-EU-Q-47 moderately correlated with NVS $(r=0.14)$, as did the short version, HLS-EUQ16 ( $\mathrm{r}=0.09)$ [53]. In terms of concurrent validity, the short version was significantly correlated with the long version $(r=0.82)$. Test-retest reliability was reported for one instrument and was demonstrated to be strong $(r=$ 0.98) for REALM-Teen [50]. Although the authors of the NVS study claim that the instrument is valid, they further explain that children younger than nine years had difficulties answering the questions [52].

Additionally, Hubbard and Rainey [41] selected items from the HEAP database, which they report to have proven content validity and reliability, as do Massey et al. [47], regarding some of their questionnaire items that were taken from other sources. Schmidt et al. reported the inclusion of some questionnaire items from the German KiGGS survey [55], which have been proven to be valid and reliable [43].

\section{Health literacy and contextual factors}

This review identified five instruments that measured health literacy related contextual factors [42, 43, 47, 49, 53]. These asked for stated satisfaction with healthcare professionals, media sources, or in the context of health learning [42, 47], parent-child communication [43], perceived availability of social resources in form of help and support [49], or perceived difficulties in the social or media interaction [53]. The other instruments focused solely on individual skills or did not provide any information related to contextual factors. However, most studies focused on three main context arenas: healthcare, prevention, and health promotion, including health education (see Table 2).

\section{Underlying health literacy understandings}

Each instrument used a different, study-specific understanding of health literacy, and two instruments were underpinned with a health literacy definition that was specifically developed for the instrument $[40,53]$. In the other 13 studies [41-52, 54], the researchers referred to different existing definitions but did not make clear whether or not these definitions were underlying their instruments, and of these, six studies [42, 43, 46-49] referred to the definition provided by Nutbeam $[8,56]$. A further five articles [42, 47, 48, 51, 52] quoted the 
Healthy People 2010 definition [57], the definition of Ratzan and Parker [58] or that of Parker and Ratzan [9], and the definition by Zarcadoolas and Pleasant [59]. One study [54] did not refer to a specific definition. Instead, the authors emphasised two different models as important for their tool, the HLS-EU model [1] and the Health Belief Model (HBM) [60]. Finally, one study [46] referenced the definition developed by Mancuso [61].

The analysis revealed three different conceptual approaches that underpin the instruments: health literacy was based on (i) a functional literacy model in three studies [50-52], (ii) school health education standards from different countries in five studies [40-42, 45, 46], and (iii) broader multidimensional models in seven studies $[43,44,47-49,53,54]$. In one of the studies the researchers claimed that their instrument measured functional health literacy by assessing knowledge, whilst the knowledge questions were based on school health education curriculum [46]. Although knowledge is highlighted as a main component of functional health literacy [8], this instrument was nevertheless instead classified under the second category rather the 'functional literacy' category.

\section{Scope of measured components}

To ascertain the scope of the measurement approach, a content analysis of the measured components (sometimes referred to as "dimensions") was performed that could identify a wide array of skills, competencies, abilities, or certain actions covered by the instruments. To closely relate to the original published study and thereby avoid any false interpretation, we decided to label a specific component as if the authors of the original article had named it explicitly. For example, in Brown et al. [40], the authors explicitly state that their instrument measures understanding, accessing, and applying health information as well as beliefs, attitudes, and interests towards health. Based on this, six components could be identified: understand, access, apply, belief, attitude, and interest. In Chisolm and Buchanan [51], the authors explain that their instrument intends to measure reading ability and numeracy skills. Therefore, we extracted two components, reading and numeracy. We applied this coding scheme to all identified articles. In total, the 15 instruments comprised 31 different components (see Table 3 and Fig. 2). The ability to understand health information was identified in six studies [40-42, 44, 48, 53] and was the most prominent approach to measure health literacy, followed by four studies that asked about the ability to access health information [40, 41, 49, 53]. The health literacy components appraise, attitude, communicate, knowledge, reading, and numeracy were found in each of the three instruments. Many different components, such as problem-solving, self-management, coping, and self-efficacy, were each assessed in only one instrument.

\section{Discussion}

The main objective of this review was to systematically identify, retrieve, analyse, and assess available generic health literacy measurement tools for children and adolescents $\leq 18$ years old. Despite the gap in health literacy research on children and adolescents, our search found 15 available generic measurement tools published between 1990 and 2015. This is the second known systematic review on health literacy measurement tools for children and adolescents. The previous one was conducted by Ormshaw et al. [38] and considered tools published until 2011. By encompassing domain-specific health literacy measures as well, their review had a somewhat different focus than this present review. Ormshaw et al. identified 16 tools for children and/or adolescents, including tools for measuring mental health literacy, media health literacy, or oral/dental health literacy. It should also be noted that their review included studies using the same instrument, for example, TOFHLAd and questions based on the National Health Education Standards (NHES, USA), whereas the present review includes an instrument only once. Therefore, the present study only has six instruments in common with that review $[40,41,43,44,48,51]$.

\section{Country of origin and setting}

While seven health literacy instruments (nearly 50\%) have been used in North America [40, 41, 44, 47, 5052], all but one [44] in the USA, six instruments have been developed and used in Europe [42, 43, 46, 48, 49, 53]. However, health literacy measurement tools for children and adolescents remain a marginalised area of research in Asia [45] and Africa [54], with only one instrument found for each region. The authors of this review are aware of instruments used in Asia that had yet not been published in English while preparing this article [62-64]. However, our search has not identified any generic health literacy instruments for South America or Australia. Given that Australia is one of the pioneering areas of health literacy research and action in childhood and adolescence, primarily in the context education [28, 65], this result is especially surprising. In relation to Africa, while the short form of the MaHeLi scale was adapted to the settings in Uganda, it was originally a European-based instrument [54]. Health literacy research in Africa, a continent with approximately 60 countries with more than one billion inhabitants and serious health threats to children and adolescents [66], has only recently begun and thereby is calling for an 'African health literacy scheme' and proportionate solutions [67]. Given the 
Table 3 Scope of measured components

\begin{tabular}{|c|c|c|c|c|c|c|c|c|c|c|c|c|c|c|c|}
\hline \multirow[t]{2}{*}{ Component } & \multicolumn{15}{|c|}{ Study no. (for study numbers see Table 2) } \\
\hline & 1 & 2 & 3 & 4 & 5 & 6 & 7 & 8 & 9 & 10 & 11 & 12 & 13 & 14 & 15 \\
\hline Understand & & $x$ & $x$ & & $x$ & $x$ & & $x$ & & & & & $x$ & & \\
\hline Access & & $x$ & $x$ & & & & & & & $x$ & & & $x$ & & \\
\hline Apply & & $x$ & & & & & & & & & & & $x$ & & \\
\hline Interest & & $x$ & & & & & & & & & & & & & \\
\hline Belief & & $x$ & & & & & & & & & & & & & \\
\hline Attitude & & $x$ & & & & & $x$ & & $x$ & & & & & & \\
\hline Reading & & & & $x$ & & & & & & $x$ & & & & X & \\
\hline Communication & & & $x$ & & & & $x$ & & & & & & & & $x$ \\
\hline Decision-making & & & $x$ & & & & & & & & & & & & \\
\hline Goal-setting & & & $x$ & & & & & & & & & & & & \\
\hline Self-management & & & $x$ & & & & & & & & & & & & \\
\hline Numeracy & & & & $x$ & $x$ & & & & & & & & & $x$ & \\
\hline Seeking & & & & & $x$ & & & & & & & $x$ & & & \\
\hline Design of experiments \& sample & & & & & $x$ & & & & & & & & & & \\
\hline Knowledge & & & & & & & $x$ & & $x$ & & $x$ & & & & \\
\hline Behaviour (health practice) & & & & & & & $x$ & & $x$ & & & & & & \\
\hline Self-efficacy & & & & & & & $x$ & & & & & & & & \\
\hline Capabilities for empowerment & & & & & & & $x$ & & & & & & & & \\
\hline Satisfaction (i.e. asking, requesting, etc.) & & & & & & $x$ & & & & & & & & & \\
\hline Received health education & & & & & & $x$ & & & & $x$ & & & & & \\
\hline Evaluate & & & & & & & & $x$ & & & & & & & \\
\hline Writing & & & & & & & & & & $x$ & & & & & \\
\hline Appraisal & & & & & & & & & & $x$ & & & $x$ & & $x$ \\
\hline Patient-provider encounter & & & & & & & & & & $x$ & & $x$ & & & \\
\hline Interaction / Navigation & & & & & & & & & & & & $x$ & & & \\
\hline Rights and responsibilities & & & & & & & & & & & & $x$ & & & \\
\hline Confidence & & & & & & & & & & & & $x$ & & & \\
\hline Coping skills & & & & & & & & & & & & & & & $x$ \\
\hline Problem solving & & & & & & & & & & & & & & & $x$ \\
\hline Word recognition & $x$ & & & & & & & & & & & & & & \\
\hline Pronunciation & $x$ & & & & & & & & & & & & & & \\
\hline
\end{tabular}

social, cultural, economic, and political differences between regions, it is especially important that research in these regions engages in health literacy with children and adolescents to facilitate better health promotion despite the challenges that these populations face. Development of more culturally sensitive concepts and measurement tools in these regions would also support this approach. In turn, and due to migration to Western countries from within these regions, health promotion and prevention in migrant and refugee child/adolescent populations in Europe and North America in particular could benefit by such approaches when adapting these tools and concepts.
Regarding the settings in which health literacy was measured, it seems that schools and other educational settings are main loci of interest for measuring the health literacy of children and adolescents. This review found that many health literacy tools are based on school health topics or curricula [40-46, 48]. When researchers aim to derive an understanding of health literacy for children and adolescents, an existing health literacy-related school curriculum could provide the necessary information and would also ensure comparable instruments and models. Shaping of school health topics to match health literacy content, therefore, would foster further development and the use of comparable 


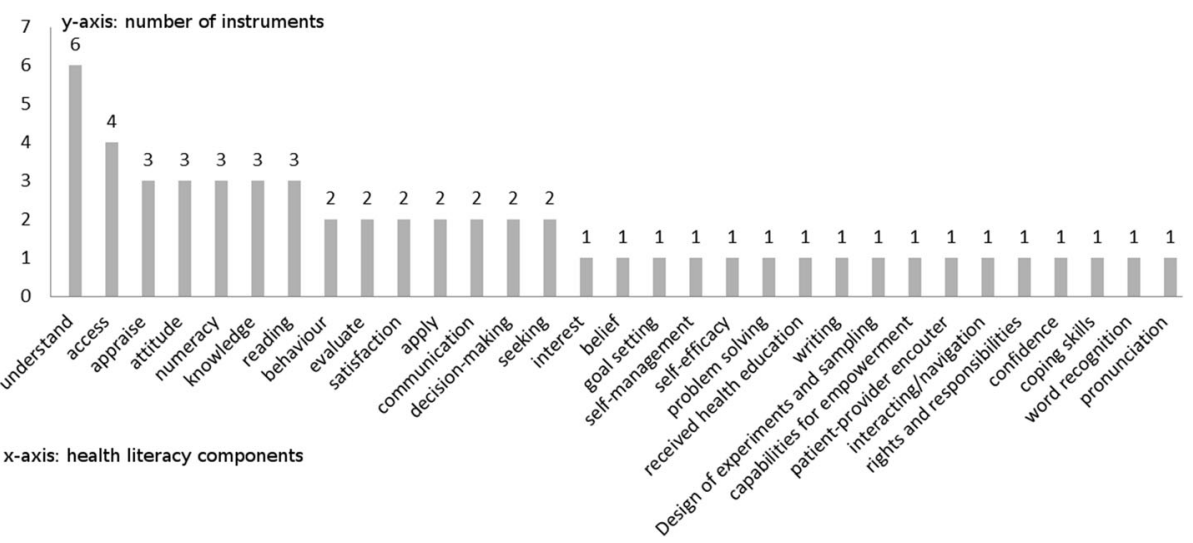

Fig. 2 Health literacy components used in the instruments

instruments, at least within countries, which would allow for consistent monitoring and evaluation of health literacy in these settings.

\section{Target or age group}

The findings of this review suggest that the age groups from 11 to 18 years are well reflected by existing health literacy tools (see Table 2). This review was able to identify a total of 15 instruments that were used with children within those age groups [40-54]. However, only five of these tools had been used to measure health literacy of children younger than 11 years old $[40,43,45,50$, 52]. One instrument was used with children aged 7 to 12 years old within a parent-child study [52]. In this study, the authors reported difficulties for children younger than 9 years old when administering the questionnaire [52]. This finding is supported by another study using this instrument in that age group [68]. One instrument was used in a study specifically conducted in the primary school setting in China without providing the exact ages of the children who participated [45]. However, we assume that the children were most likely between 6 and 10 years old, which is the common age of primary school-aged children in China. The same study also used their instrument with secondary school children, but they did not provide any information on differences in using this tool between age groups. Two instruments were used with secondary school children aged 9 to 13 years $[40,43]$. Although it is most common that children 9 and 10 years old usually attend primary schools rather than secondary schools, in those two studies, the children were nevertheless reported to be students at secondary schools. Together with the Chinese instrument [45], these two $[40,43]$ were also the only instruments that were specifically developed for children younger than 11 years old. The other two instruments were adaptations of the REALM [50] and NVS [52] studies. With only one instrument specifically developed for the use in primary school-aged children [45], our findings emphasise that there might be only one health literacy instrument available for primary school children. Unfortunately, the authors do not provide adequate information that might facilitate a better understanding of their instrument. In conclusion, there is a lack of adequate information on health literacy instruments for primary school children and no instruments available to assess the health literacy of children younger than seven except the Chinese tool [45].

Health literacy is important for young children, but the conceptualisation and measurement of health literacy are different from the approach taken with adults. Existing health literacy concepts specific to adults address how people understand, evaluate, and use health information, which may not be appropriate for children of primary school age who are not making all the health-related decisions that affect them. Not only do such approaches demand more complex skills to process health information, but an individual also needs more experience and autonomy to be able to judge the quality of information or to act based on given, sometimes complex, information. Primary school-aged children are still developing their formative skill sets that are required to process health information, and they will have acquired far less health-related knowledge and experience and have less autonomy than adults or older children $[14,17$, 18, 20, 22, 26-28]. Therefore, health literacy concepts and their assessment in this age group have to be less complex and should focus on more basic aspects of health promotion and education, such as healthy eating, physical activity, or knowledge about their bodies and the environment. Arguably in healthcare contexts, the health literacy of the parents of young children is more likely to be important and have greater impact than is that of the young children themselves, as the parents are those who communicate with professionals and make the influential health-related decisions. These assumptions are 
also supported by two studies that reported on cognitive difficulties experienced by younger children during the administration of health literacy instruments $[52,68]$.

\section{Questionnaire administration mode: Objective and subjective measurement}

Half of the identified tools were subjective measurement tools and asked the participants for an assessment of their self-perceived health skills and half were objective measurement tools and assessed the actual capabilities by performance testing. Only one tool combined both assessment methods [43]. Although self-reported health literacy measurement has been used in many studies and instruments [4, 32], there is much criticism concerning self-reporting as a valid measure of health literacy [33, $44,49,69-72]$. It is argued that self-reporting measures are oversimplifying the given complexity of health literacy [49], or, in some cases, assess self-efficacy rather than health literacy [33]. Furthermore, a discrepancy between self-reported health literacy and the actual performance related to health literacy has been highlighted indicating concerns with self-reporting measures in terms of accuracy [33, 44, 49]. Other research suggests that self-reporting methods are just as valid as objective methods [73]. Ethical concerns related to objective measures, however, have highlighted the potential discomfort that participants with low health literacy skills may feel if they are ashamed or embarrassed by their abilities [73, 74]. For future health literacy research with children and adolescents, adopting a combination of both methods might prove a valuable way in order to generate more detailed and profound data. It would also allow for the comparison of differences in health literacy as measured with these two different methods. Applying different research methods may also generate richer results and, therefore, would support the development of better and more problem-centred interventions to address specific health literacy weaknesses.

\section{Participant inclusion in questionnaire development}

Including participants in the development of a health literacy questionnaire has proven to be a sound method to improve the quality of the measurement tool [75]. Regarding the development of new and innovative health literacy tools, it is recommended always to include the target population in the development process as early as possible [76]. However, analysis of this review showed that children are mostly excluded from the development of the instrument and/or the conceptual construction that underpins the questionnaire. With only two reporting qualitative research with adolescents and/or adults during the development process of the instrument [47, 49], child and adolescent involvement was poor. In none of the studies were children younger than 13 years old actively involved, except for completing the questionnaires. Accordingly, this review found adult experts setting out to define a concept for children and young people without consulting them to determine their understanding of health literacy and assuming the healthrelated skills and knowledge and health behaviours and practices that may be important for them in their everyday lives. This conflicts with theories and findings from childhood studies that consider children and adolescents to be active citizens, social agents, and co-constructors of their social worlds $[77,78]$. Researchers from this field also highlight that children should be understood as a social minority living in a "childhood" with unequal power relations, that they suffer from an uneven distribution of rights, and that one major weakness in research and practice is that childhood is mainly constructed by adults $[28,77,78]$. Although two studies valued contributions from adolescents as useful sources of qualitative information, there is considerable room for improving child/adolescent participation in the health literacy research process, especially as there are yet no studies including young children in the development of instruments. Therefore, little is known about what health literacy means to children, what knowledge and skills are important to them in order to promote their health, or how, where, when, with whom, and why (or why not) they are interested in developing skills in order to promote their own health. To learn more from children and to learn collaboratively with them, their active involvement and participation in the social and cultural construction of health literacy and its measurement is a specific challenge that would be highly beneficial to overcome for research with children. In not doing so, an important voice, the children's perception of health and health literacy, is not recognised and given the consideration that it deserves in the field of health literacy research. Although, few studies have performed qualitative health literacy research with children $[29,62]$, in recent years, especially in health-related disciplines (for example, mental and dental health), qualitative research with children has increased [79-82]. Researchers argue that the benefits of children's involvement by using qualitative research methods are obvious and include enhancing child empowerment, producing better knowledge and understanding of children's views and priorities, and developing better tools and practice measures for more effective action [79, 81]. Additionally, as such, it could be argued that applying qualitative methods in health literacy research with children would have similar effects and thus produce more precise findings and unravel children's own perspectives and knowledge related to health. Such findings could be used to derive a child-centred understanding of health literacy and elucidate the underlying tenets of children's health 
literacy. Furthermore, children's participation could also support the development of more child-adjusted measurement tools and facilitate the development of tailored health literacy interventions that better match the needs and demands of this population.

\section{Psychometric properties}

The results concerning the validation processes are diverse. Only a few studies provide validation data on the instrument [44, 48-51,53], and most instruments have weak or only moderate validity. The focus of reporting in these studies is on statistical population data, results, and sample characteristics, while reporting on methodological data and psychometric properties is scarce and not well described. These results confirm findings from other systematic reviews with different foci [31, 32, 37]. Only one article made test-retest-reliability data available [50]. To support better clarity on the characteristics of tools, the authors should provide more detailed information on the development and validation process, psychometric properties, and assessment characteristics.

\section{Health literacy and contextual factors}

There has been much debate in the conceptual and methodological discussion regarding adult populations as to whether health literacy is only associated with individual abilities, or if beyond individual abilities, context also might have an essential impact on the health literacy of individuals $[1,9,10,16,21,33,58,59,70,71,83-$ 85]. Similarly, the influence of context is also discussed within the scientific literature related to children's health literacy $[14,20,22-28]$. It seems that the scientific community generally agrees that context is an important dimension that should be considered appropriately and that health literacy itself is a relational concept that is influenced by more than only individual abilities. In general, when the relatedness of health literacy is being discussed, the context dimension is mainly meant to capture the complexities and demands of the health system and the health literacy of health professionals, particularly in relation to the health literacy of individuals that they interact with in certain health literacy related situations $[9,16,58,85]$. This also includes information materials being tailored and user-friendly and communication being based on understandable and simple language [85]. In this context, the identified measurement tools, however, did not provide much information because most of the tools focused on measuring individual abilities rather than contextual factors with impact on health literacy. However, when the context dimension is extended to also address contextual factors beyond health system complexities, there are some findings that can be reported. Overall, the analysis could identify five instruments that included questionnaire items addressing contextual factors or situational determinants that might influence health literacy [42, 43, 47, 49, 53]. In relation to health literacy, one instrument assessed the stated satisfaction of adolescents in the context of health learning in schools [42]. Another questionnaire asked adolescents about the confidence that they feel when they try to access health information from personal and media sources [47]. Two instruments included broader context questions in relation to self-perceived difficulties with respect to health literacy and thereby asked about the trustworthiness and meaning of health information and sources, the possible impact of the social and political environment on health, and the interaction with health professionals $[49,53]$. Finally, one instrument included questions related to children's communication habits with their social environment (friends/parents) [43]. Apart from collecting data on individual abilities, asking such questions related to emotions, attitudes, opinions, and interests within the context of specific health literacy situations seems to be a promising approach that could support the derivation of a broader understanding of the interplay between individuals and their health-related environment. In addition, it allows for encountering valuable insights from individuals and how they perceive the influence of context on their health literacy and health practices.

Context can also be understood as the setting in which individuals use their health literacy or interact with others, such as in healthcare and medicine, disease prevention, health promotion, everyday life, and educational settings. In this context, our review has found several health literacy instruments that are related to different contexts and their inherent characteristics. While the health literacy instruments used within the educational setting had a dominant focus on health promotion resources and prevention [40-46], studies conducted in hospitals or medical centres addressed various aspects of the healthcare environment by asking questions, i.e., on treatment, self-management, and interaction with health professionals [47, 49-52, 54]. Two instruments were found that addressed mixed contexts, including healthcare, prevention, and health promotion and education $[48,53]$.

However, to provide meaningful data on the impact of context on individual health literacy, future health literacy measurement tools for children and adolescents should include more questions related to contextual factors. In addition, tailored questionnaires could also be administered simultaneously in dependent populations within the same study, for example, involving teachers and students, patients and health professionals, or parents and children, including questions on the various inherent intricacies of complex contexts as discussed within the conceptual health literacy literature. This 
would ensure the capture of both sides of the health literacy concept, the individual and its related context.

\section{Underlying health literacy understandings}

Health literacy measurement tools for both adults and children/adolescents have been criticised for different reasons $[33,38,86]$. First and foremost, the lack of a consistent general understanding of health literacy is highlighted as a major weakness within the field [1,33, $76,85]$ that affects the development of comparable methods to accurately measure the concept $[33,85]$. This review supports this finding, as each of the identified instruments introduced an individual and/or studyrelated understanding of health literacy. This makes it difficult to compare the instruments or the results generated by these instruments. Even instruments that apply similar conceptual approaches vary considerably in how they transfer the underlying concepts into questionnaire items at the operational level. Three instruments, for example, measure functional literacy [50-52], which can be described as a unidimensional approach to health literacy and sometimes is referred to as medical health literacy [1, 83, 84, 86]. Even though REALM-teen [50], TOFHLAd [51], and NVS [52] are tools that measure functional literacy, they are however testing different components of the literacy construct, such as reading, comprehension, and numeracy. Another tool addressing functional 'health literacy' is the "health quiz" measurement tool [46]. However, it is based on the functional concept of health literacy as proposed by Nutbeam [8], measuring knowledge rather than literacy, as in the previously mentioned tools [50-52].

Compared to the narrow 'functional literacy' approach to health literacy, all other instruments $(n=12)$ are informed by a multidimensional, multifactorial, or multifaceted and thus broad understanding of health literacy. Still, each understanding is more or less unique, and therefore, comparisons across these health literacy assessment instruments and associated study results are difficult to undertake. Additionally, as the instruments do not cover all their proposed dimensions and components at the operational level, there seem to be some uncertainties regarding how to transform all aspects of the theoretical model into a testable concept within a measurement tool. It is also not clear why a certain model or definition is provided at the conceptual level when at the operational level, something else is indeed being measured. However, when school health education (or other educational contents and contexts) is the foundation of the health literacy framework, it seems that there is more precise clarification as to why, how, and for what purpose a model was designed and operationalised [40, 42-45]. If an instrument has been based on a clear conceptual model, it is much more feasible to clearly understand what is assessed by the construct [43, 47-49, $53,54]$. However, in some studies, the operational definition covers only select aspects of the conceptual definition [40, 41, 43, 53, 54].

\section{Scope of measured components}

When researchers measure health literacy, there is a wide array of components at the operational level that can be assessed by instruments [4,38]. This review was able to identify a total of 31 different components that were addressed by 15 different instruments (see Table 3). As these studies each provide a different understanding of health literacy, including the chosen components to reflect upon, neither the conceptual/operational definitions nor the instruments were found to be comparable to one another, although some instruments apply and assess similar components. Moreover, not all authors provide their questionnaire items or make them accessible elsewhere, which makes understanding the tools difficult and prevents an accurate evaluation of exactly how each component was measured or indeed if it was measured at all. Thus, it is not possible to assess how far the predefined concept is represented in the questionnaire items or scales. Accordingly, we argue here that authors should make it quite clear which aspects of the model they intend to measure and which they actually do measure, and explain why they measure in that way. Of course, providing the questionnaire items could additionally support a better understanding of the instrument and the operationalisation of the underlying concept, if applicable. Despite the importance given to the social and cultural dimensions of health literacy [1, $8,14,16,21,26,27,56,59]$, most instruments fail to address measurable components related to cultural competencies or social skills making it difficult to evaluate their actual impact on individual's health literacy. Further components that are considered important to health literacy, such as empowerment, attitude, and selfefficacy [8], can be found in few instruments [40, 43, 45, 47].

\section{Limitations}

This review has several limitations. Not all identified studies provided the questionnaire items which makes it difficult to undertake an accurate evaluation of the instrument without knowing how the construct was operationalised. This becomes even more critical if the components are only loosely described. In some cases, in which studies did not provide the questionnaire, the authors could be asked to provide the instruments to undertake further analysis with more detail. Unfortunately, several promising studies on health literacy measurement tools for children and adolescents, were not available in German or English [62-64]. In the 
systematic review of Ormshaw et al. [38], further domain-specific and generic health literacy measurement tools for children and adolescents are reported. Having also analysed these studies during our review process, the authors of the original studies cited by Ormshaw et al. [38] did not provide necessary information to match the inclusion criteria of this review. Either some of the described instruments were used in studies we had already included, such as adaptations of TOFHLA, REALM, and NVS, or the articles did not describe the instruments in the necessary detail. Thus, these instruments were not included in this present review. However, these instruments may provide useful information for the development of new health literacy tools for children and adolescents. Furthermore, as health literacy is seen by some as a repackaging of the already existing concepts of health promotion and education, such as empowerment, self-efficacy, life skills, and the community approaches $[87,88]$, it may be useful to consider the methodology by which these concepts are being measured. For example, life skills measures could provide useful information for health literacy as well. This impression is supported by Sørensen and Brand [89], who reflected on the different translations and contexts of health literacy in which life skills or health-related competencies are used sometimes as synonyms for health literacy.

Regarding general limitations in the context of the health literacy measurement tools that were investigated during this study, the measurement of health literacy in children and adolescents is particularly difficult for two reasons. Firstly, there is no commonly accepted health literacy model or definition. In fact, there are approximately 250 different definitions or models available for adults [90], while there is a significantly smaller number available for children and adolescents [91]. Various constructions co-exist but are indeed fundamentally different, and they are apparently associated with uncertainties with respect to their measurement. The understanding that informs an assessment tool defines what kind of health literacy interpretation is measured. It is no surprise that across studies and tools dedicated to the assessment of health literacy, health literacy itself can be a different construct in each case. To progress in the field of measurement tools, consensus is essential in the conceptual field. Secondly, and in addition to conceptual concerns, another important issue is related to the cognitive and social development of children, which should be seriously considered when addressing the measurement of health literacy. Developing adequate health literacy levels requires certain prerequisites, such as skills; knowledge; level of experience with regard to health; autonomy and independence; and acquired social skills. Considering current conceptualisations of health literacy and how they are being measured, it is questionable whether young children will have acquired the competencies required to undertake the complex processing of health information as demanded by most of the existing health literacy models. As the achieved skill sets of children vary enormously across age groups and diverse backgrounds, there might be a need for age-appropriate and developmental-stage-adjusted concepts and their operationalisation considering the actual (social and cognitive) capabilities of children at different ages during childhood and adolescence.

\section{Conclusion}

This article sought to systematically review the field of children's and adolescents' generic health literacy measurement instruments and provides a detailed analysis of these instruments. Health literacy research with younger age groups is a growing field. However, methodological approaches require further improvement. In terms of conceptual and operational definitions, it seems that instrument development first needs a clear conceptual understanding of health literacy that should be transferable to an operational definition that covers all aspects of that understanding [33]. This is supported by findings presented in this review, and similar observations on theoretical definitions not matching the operational definition have been made [37, 47, 85, 92]. Furthermore, given the lack of a specific and explicit health literacy definition and/or if the understanding is vaguely based on different definitions and models, it is far more difficult to understand how the conceptual model has been operationalised. To date, there is scarce data for constructing an effective blueprint for health literacy measurement instruments. Furthermore, there is currently a specific gap regarding health literacy measurement instruments aimed at primary school and early childhoodaged children. From a methodological perspective, when health literacy instrument studies are designed, especially for children, they should consider a mixed-method approach combining both subjective and objective measurement approaches. This would allow for the comparison of results and would secure the validity and reliability of the instruments. Although there are currently no findings from general health literacy research with children that specifically articulate the involvement of children in the development of measurement tools, research with children conducted in other disciplines shows the benefits of children's involvement. Children's meaningful involvement in health literacy research could be as beneficial as it is currently in dental health and mental health research. It could, for example, enlighten researchers in terms of a better understanding of children's views, interests, perceptions, feelings, interactions, and worlds, which then could be used to develop models 
and measurement tools that are better suited to children. Furthermore, recent studies highlight the importance of meeting the specific health literacy needs of children and adolescents [5, 20, 28]. This includes development of materials and information that are suited to younger age groups and provided in ways that engage and empower them or improve uptake $[5,26,27]$. This may well foster an improvement in the development of health literacy throughout life, beginning in early childhood.

Currently, the valid measurement and assessment of child and adolescent heath literacy are gaining importance in terms of monitoring and evaluating the effects of health literacy promotion in children and adolescents. In accordance with this, many scholars have recently called for advancing health literacy measurement $[33,85,86$, 92, 93], including child-specific instruments [26, 38]. With this work, the authors hope to stimulate further scientific research and action, especially concerning health literacy measurement development as well as intervention and policy development. The results of this review will be of value and considerable interest to researchers and practitioners interested in health literacy measurement as it explains which instruments already exist and how they were developed, applied, tested, and validated.

\section{Additional files}

Additional file 1: PRISMA study protocol. (PDF 384 kb)

Additional file 2: Search methodology. (PDF 201 kb)

\section{Acknowledgments}

The authors thank all researchers at the Centre for Prevention for Intervention in Childhood and Adolescence (CPI) at Bielefeld University and all partners in the HLCA consortium for contributing to the discussion of the results and the content of this article. CPI can be found online at: www.unibielefeld.de/(en)/zpi; HLCA can be found online at: www.hlcaconsortium.com

\section{Funding}

The HLCA consortium is funded by the Federal Ministry of Education and Research (BMBF) from March 2015-February 2018. Funding code: 01EL1424A.

\section{Availability of data and materials}

All data generated or analysed during this study are included in this published article [and its supplementary information files].

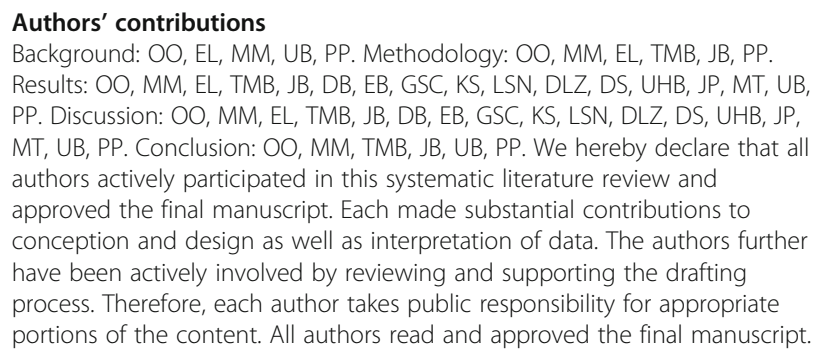
Results: OO, MM, EL, TMB, JB, DB, EB, GSC, KS, LSN, DLZ, DS, UHB, JP, MT, UB, PP. Discussion: OO, MM, EL, TMB, JB, DB, EB, GSC, KS, LSN, DLZ, DS, UHB, JP, MT, UB, PP. Conclusion: OO, MM, TMB, JB, UB, PP. We hereby declare that all authors actively participated in this systematic literature review and approved the final manuscript. Each made substantial contributions to conception and design as well as interpretation of data. The authors further have been actively involved by reviewing and supporting the drafting process. Therefore, each author takes public responsibility for appropriate portions of the content. All authors read and approved the final manuscript.

Ethics approval and consent to participate Not applicable.
Consent for publication

Not applicable.

\section{Competing interests}

The authors are active members of the German National Health Literacy in Childhood and Adolescence Research Consortium (HLCA) and declare to have no competing interests.

\section{Publisher's Note}

Springer Nature remains neutral with regard to jurisdictional claims in published maps and institutional affiliations.

\section{Author details}

${ }^{1}$ Faculty of Educational Science, Centre for Prevention and Intervention in Childhood and Adolescents (CPI), Bielefeld University, Bielefeld, NRW, Germany. ${ }^{2}$ School of Public Health, Public Health Nursing \& Health Science Research, Bielefeld University, Bielefeld, NRW, Germany. ${ }^{3}$ University of Suffolk, Ipswich, England, UK. ${ }^{4} \mathrm{CIEC}$, Institute of Education, University of Minho, Braga, Portugal. ${ }^{5} \mathrm{Global}$ Health Literacy Academy, Urmond, The Netherlands. ${ }^{6}$ CIESP, National School of Public Health, ISAMB (FMUL), Universidade NOVA de Lisboa, Lisbon, Portugal. 'S School of Public Health, University of Haifa, Haifa, Israel. ${ }^{8}$ School of Education, University of Applied Sciences and Arts, Northwestern Switzerland, Basel, Switzerland. ' University of Education, Freiburg, i.Br, Germany. ${ }^{10}$ Austria \& Institute for Public Health, University of Vienna, Vienna, Austria. ${ }^{11}$ School of Education, Aberystwyth University, Aberystwyth, Wales. ${ }^{12}$ Clalit Health Services, Department of Health Education and Promotion, Tel Aviv, Israel.

Received: 21 December 2016 Accepted: 10 January 2018 Published online: 22 January 2018

\section{References}

1. Sørensen K, van den Broucke S, Fullam J, Doyle G, Pelikan J, Slonska Z, Brand $\mathrm{H}$. Health literacy and public health: a systematic review and integration of definitions and models. BMC Public Health. 2012;12:80. https://doi.org/10.1186/1471-2458-12-80.

2. Sykes S, Wills J, Rowlan DG, Popple K. Understanding critical health literacy: a concept analysis. BMC Public Health. 2013 Feb 18;13:150. https://doi.org/ 10.1186/1471-2458-13-150.

3. Koh HK, Berwick DM, Clancy CM, Baur C, Brach C, Harris LM, Zerhusen EG. New federal policy initiatives to boost health literacy can help the nation move beyond the cycle of costly 'crisis care'. Health Affairs (Millwood). 2012 Feb;31(2):434-43. https://doi.org/10.1377/hlthaff.2011.1169.

4. Haun JN, Valerio MA, McCormack LA, Sørensen K, Paasche-Orlow MK. Health literacy measurement: an inventory and descriptive summary of 51 instruments. J Health Commun. 2014;19(Suppl 2):302-33. https://doi.org/10. 1080/10810730.2014.936571.

5. Zamora $\mathrm{P}$, Pinheiro $\mathrm{P}$, Okan $\mathrm{O}$, Bitzer E-M, Jordan S, Bittlingmayer UH, et al. Health Literacy im Kindes- und Jugendalter. Prävention und Gesundheitsförderung. 2015;10:167-72. https://doi.org/10.1007/s11553015-0492-3.

6. McDaid D. Investing in health literacy: What do we know about the cobenefits to the education sector of actions targeted at children and young people? Policy briefs and summaries. World Health Organization Regional Office for Europe. European Observatory on Health Systems and Policies. 2016. http://www.euro.who.int/_data/assets/pdf_file/0006/315852/PolicyBrief-19-Investing-health-literacy.pdf. Accessed 9 Sep 2016.

7. World Health Organization. Shanghai declaration on promoting health in the 2030 agenda for sustainable development. Health Promot Int. 2017; 32(1):7-8

8. Nutbeam D. Health literacy as a public health goal: a challenge for contemporary health education and communication strategies into the 21st century. Health Promot Int. 2000;15:259-67. https://doi.org/10.1093/heapro/ 15.3.259.

9. Parker R, Ratzan SC. Health literacy: a second decade of distinction for Americans. J Health Commun. 2010;15(Suppl 2):20-33. https://doi.org/10. 1080/10810730.2010.501094

10. Sørensen K, Pelikan JM, Röthlin F, Ganahl K, Slonska Z, Doyle G, et al. Health literacy in Europe: comparative results of the European health literacy survey (HLS-EU). Eur J Pub Health. 2015 Dec;25(6):1053-8. https://doi.org/10. 1093/eurpub/ckv043. 
11. Berkman ND, Sheridan SL, Donahue KE, Halpern DJ, Crotty K. Low health literacy and health outcomes: an updated systematic review. Ann Intern Med. 2011 Jul 19;155(2):97-107. https://doi.org/10.7326/0003-4819-155-2201107190-00005.

12. Simonds SK. Health Education as social policy. Proceedings of the will Rogers Conf on health education, Saranac Lake, NY June 22-23, 1973. Health Educ Monogr. 1974;2(Suppl 1):1-10.

13. Abrams MA, Klass PK, Dreyer B. Health literacy and children: introduction. Pediatrics. 2009 Nov;124(Suppl 3):S262-4. https://doi.org/10. 1542/peds.2009-1162A.

14. Paakkari L, Paakkari O. Health literacy as a learning outcome in schools. Health Educ. 2012;112(2):133-52. https://doi.org/10.1108/ 09654281211203411

15. Manganello JA. Health Literacy and adolescents: a framework and agenda for future research. Health Educ Res. 2008;23:840-7. https:/doi.org/10.1093/her/ cym069.

16. Nielsen-Bohlman L, Panzer AM, Kindig DA. Health literacy - a prescription to end confusion. Washington (DC): THE NATIONAL ACADEMIES PRESS; 2004.

17. Britto PR, Engle PL. Super CM. Handbook of early childhood development research and its impact on global policy: Oxford University Press; 2013

18. Halfon N, Larson K, Lu M, Tullis E, Russ S. Lifecourse health development: past, present and future. Matern Child Health J. 2014 Feb;18(2):344-65. https://doi.org/10.1007/s10995-013-1346-2.

19. Liew J. Effortful control, executive functions, and education: bringing selfregulatory and social-emotional competencies to the table. Child Dev Perspect. 2012 Jul;6(2):105-11. https://doi.org/10.1111/j.1750-8606.2011. 00196.x.

20. Borzekowski DLG. Considering children and health literacy: a theoretical approach. Pediatrics. 2009;124:282-8. https://doi.org/10.1542/peds.2009-1 162D.

21. Rootman I, Gordon-El-Bihbety D. A vision for a health literate Canada. Ottawa, ON: Canadian Public Health Association; 2008.

22. Paakkari $\mathrm{L}$. Three approaches to school health education as a means to higher levels of health literacy. In: Simovska V, Mannix McNamara P, editors. Schools for health and sustainability, Springer Netherlands, vol. 2015; 2015. p. 275-89.

23. Hagell A, Rigby E, Perrow F. Promoting health literacy in secondary schools: a review. British Journal of School Nursing. 2015:10:82-7.

24. Kilgour L, Matthews N, Christian P, Shire J. Health literacy in schools: prioritising health and well-being issues through the curriculum. Sport Educ Soc. 2015;20(4):485-500. http://dx.doi.org/10.1080/13573322.2013. 769948

25. Levin-Zamir D, Lemish D, Gofin R. Media Health literacy $(\mathrm{MHL})$ : development and measurement of the concept among adolescents. Health Educ Res. 2011;26:323-35. https://doi.org/10.1093/her/cyr007.

26. Okan O, Pinheiro P, Zamora P, Bauer U. Health Literacy bei Kindern und Jugendlichen. [Health literacy in childhood and adolescence. An overview and current state of research] BundesgesundheitsblattGesundheitsforschung-Gesundheitsschutz. 2015 Sep 1:58(9):930-41.

27. Okan O, Bröder J, Pinheiro P, Bauer U. Health Literacy im Kindes- und Jugendalter - Eine explorierende Perspektive. [Health literacy in childhood and adolescence: an explorative perspective] In: Schaeffer D, Pelikan J, editors. Health Literacy: Forschungsstand und Perspektiven. Bern: Huber; 2016, p. 33-53.

28. Velardo S, Drummond M. Emphasizing the child in child health literacy research. Journal of Child Health Care. 2016 Apr 18. pii: 1367493516643423.

29. Fairbrother $H_{\text {, Curtis }}$, Goyder E. Making health information meaningful: Children's health literacy practices. SSM - Population Health. 2016;2:476-84. https://doi.org/10.1016/j.ssmph.2016.06.005

30. Begoray DL, Banister EM. Adolescent Health Literacy and Learning. Public Health in the 21st Century. Nova Publishing; 2015.

31. Altin SV, Finke I, Kautz-Freimuth S, Stock S. The evolution of health literacy assessment tools: a systematic review. BMC Public Health. 2014 Nov 24;14: 1207. https://doi.org/10.1186/1471-2458-14-1207.

32. Nguyen TH, Park H, Han HR, Chan KS, Paasche-Orlow MK, Haun J, Kim MT. State of the science of health literacy measures: validity implications for minority populations. Patient Educ Couns. 2015;98(12):1492-512. https://doi. org/10.1016/j.pec.2015.07.013

33. Pleasant A. Advancing health literacy measurement: a pathway to better health and health system performance. J Health Commun. 2014 Dec 2; 19(12):1481-96. https://doi.org/10.1080/10810730.2014.954083.
34. Collins SA, Currie LM, Bakken S, Vawdrey DK, Stone PW. Health literacy screening instruments for eHealth applications: a systematic review. J Biomed Inform. 2012 Jun;45(3):598-607. https://doi.org/10.1016/j.jbi.2012. 04.001.

35. Parthasarathy DS, McGrath CP, Bridges SM, Wong HM, Yiu CK, au TK. Efficacy of instruments measuring oral health literacy: a systematic review. Oral health and preventive Dentistry 2014;12(3):201-207. doi: https://doi.org/10. 3290/j.ohpd.a32681.

36. Dickson-Swift V, Kenny A, Farmer J, Gussy M, Larkins S. Measuring oral health literacy: a scoping review of existing tools. BMC Oral Health. 2014 Dec 4;14:148. https://doi.org/10.1186/1472-6831-14-148.

37. Jordan JE, Osborne RH, Buchbinder R. Critical appraisal of health literacy indices revealed variable underlying constructs, narrow content and psychometric weaknesses. J Clin Epidemiol. 2011 Apr;64(4):366-79. https:// doi.org/10.1016/j.jclinepi.2010.04.005.

38. Ormshaw MJ, Paakkari LT, Kannas LK. Measuring child and adolescent health literacy: a systematic review of literature. Health Educ. 2013;113(5):433-55.

39. Moher D, Liberati A, Tetzlaff J, Altman DG. PRISMA group. Preferred reporting items for systematic reviews and meta-analyses: the PRISMA statement. Int J Surg. 2010;8(5):336-41.

40. Brown SL, Teufel JA, Birch DA. Early adolescents perceptions of health and health literacy. J Sch Health. 2007;77:7-15.

41. Hubbard B, Rainey J. Health literacy instruction and evaluation among secondary school students. Am J Health Educ. 2007;38(6):332-7.

42. Vardavas $\mathrm{Cl}$, Kondilis BK, Patelarou E, Akrivos PD, Falagas ME. Health literacy and sources of health education among adolescents in Greece. International Journal of Adolescent Medicine and Health. 2009 Apr 1; 21(2):179-86.

43. Schmidt CO, Fahland RA, Franze M, Splieth C, Thyrian JR, Plachta-Danielzik S, et al. Health-related behaviour, knowledge, attitudes, communication and social status in school children in eastern Germany. Health Educ Res. 2010; 25:542-51. https://doi.org/10.1093/her/cyq011.

44. Wu AD, Begoray DL, Macdonald M, Wharf Higgins J, Frankish J, Kwan B, et al. Developing and evaluating a relevant and feasible instrument for measuring health literacy of Canadian high school students. Health Promot Int. 2010;25:444-52. https://doi.org/10.1093/heapro/daq032.

45. Yu X, Yang T, Wang S, Zhang X. Study on student health literacy gained through health education in elementary and middle schools in China. Health Educ J. 2012;71:452-60. https://doi.org/10.1177/0017896911430548

46. Wallmann B, Gierschner S, Froböse I. Gesundheitskompetenz: was wissen unsere Schüler über gesundheit?. [health-related knowledge: what do our pupils know about health? An empirical study]. Prävention und Gesundheitsförderung. 2012;7(1):5-10. https://doi.org/10.1007/s11553-0110322-1.

47. Massey P, Prelip M, Calimlim B, Afifi A, Quiter E, Nessim S, et al findings toward a multidimensional measure of adolescent health literacy. Am J Health Behav 2013; 37: 342-350. doi:https://doi.org/10.5993/AJHB.37.3.7 23985181.

48. Steckelberg A, Hulfenhaus C, Kasper J, Rost J, Muhlhauser I. How to measure critical health competences: development and validation of the critical health competence test (CHC test). Advances in Health Sciences Education: Theory and Practice. 2009;14:11-22. https://doi.org/10.1007/ s10459-007-9083-1.

49. Chinn D, McCarthy C. All aspects of health literacy scale (AAHLS): developing a tool to measure functional, communicative and critical health literacy in primary healthcare settings. Patient Educ Couns. 2013 Feb;90(2):247-53. https://doi.org/10.1016/j.pec.2012.10.019.

50. Davis TC, Wolf MS, Arnold CL, Byrd RS, Long SW, Springer T, et al. Development and validation of the rapid estimate of adolescent literacy in medicine (REALM-teen): a tool to screen adolescents for below-grade reading in health care settings. Pediatrics. 2006 Dec;118(6):e1707-14.

51. Chisolm DJ, Buchanan L. Measuring adolescent functional health literacy: a pilot validation of the test of functional health literacy in adults. J Adolesc Health. 2007:41(3):312-4. https://doi.org/10.1016/j.jadohealth.2007.04.015.

52. Driessnack $M$, Chung $S$, Perkhounkova $E$, Hein M. Using the "newest vital sign" to assess health literacy in children. J Pediatr Health Care. 2014 Mar; 28(2):165-71. https://doi.org/10.1016/j.pedhc.2013.05.005.

53. Röthlin F, Pelikan JM, Ganahl K. Die Gesundheitskompetenz der 15-jährigen Jugendlichen in Österreich. Abschlussbericht der österreichischen Gesundheitskompetenz Jugendstudie im Auftrag des Hauptverbands der österreichischen Sozialversicherungsträger (HVSV). 2013; 
http://lbihpr.lbg.ac.at.w8.netz-werk.com/sites/files/lbihpr/attachments/ hljugend_bericht.pdf. Accessed 28 Jun 2015

54. Naigaga MD, Guttersrud $\varnothing$, Pettersen KS. Measuring maternal health literacy in adolescents attending antenatal care in a developing country-the impact of selected demographic characteristics. J Clin Nurs. 2015;24(17-18):2402-9.

55. Thyen $U$. The German health interview and examination survey for children and adolescents (KiGGS) 2003-2006. Bundesgesundheitsblatt Gesundheitsforschung Gesundheitsschutz. 2007;50:529-30.

56. Nutbeam D. Health promotion glossary. Health Promot Int. 1998;13(4):34964. https://doi.org/10.1093/heapro/13.4.349.

57. US Department of Health and Human Services. Healthy People 2010: understanding and improving health. 2000. http://www.healthypeople. gov/2010/document/pdf/uih/2010uih.pdf. Accessed Jul 142016.

58. Ratzan SC, Parker RM. National Institutes of Health, US Department of Health and Human Services. In: National library of medicine current bibliographies in medicine: health literacy. Bethesda: MD; 2000.

59. Zarcadoolas C, Pleasant AF, Greer DS. Advancing health literacy: a framework for understanding and action. 1st ed. San Francisco, CA: Jossey-Bass; 2006.

60. Glanz K, Rimer BK, Lewis FM, editors. Health behavior and health education: theory, research and practice. San Francisco, CA: Jossey-Bass; 2002.

61. Mancuso JM. Health literacy: a concept/dimensional analysis. Nursing \& health sciences. 2008 Sep;10(3):248-55. https://doi.org/10.1111/j.14422018.2008.00394.x.

62. Liu CH, Liao LL, Shih SF, Chang TC, Chi HY, Osborne RH. Development and implementation of Taiwan's child health literacy test. Taiwan Journal of Public Health. 2014;33(3):251-70. https://doi.org/10.6288/ TJPH201433102105.

63. Liao LL, Liu CH, Cheng CC, Chang TC. Defining Taiwanese children's health literacy abilities from a health promotion perspective. Global Health Promotion. 2016;PMID 27353116. doi:https://doi.org/10.1177/ 1757975915626114.

64. Zhang SC, Wan YH, Tao SM, Chen J, Tao FB. Reliability and construct validity of the adolescent interactive health literacy questionnaire. Chin J Sch Health. 2014;35(3):332-6.

65. St Leger L. Schools, health literacy and public health: possibilities and challenges. Health Promot Int. 2001;16:197-205. https://doi.org/10.1093/ heapro/16.2.197.

66. Unicef. Children in Africa. UNICEF Data \& Analytics. Division of Policy and Strategy. 2014. https://www.unicef.org/about/execboard/files/Africa_ Brochure_Eng_14May14.pdf. Accessed 10 May 2016.

67. Anchang KY, DeLuca L, Mshigeni K, SKK M, Dudley a, Nambu Njuakom F. Can we exploit and adapt indigenous knowledge and ethno-botanicals for a healthy living in the face of emerging diseases like Ebola in Africa. American journal of Clin Exp Med. 2015;3(1-1):24-8. https://doi.org/10. 11648/j.ajcem.s.2015030101.15.

68. Warsh J, Chari R, Badaczewski A, Hossain J, Sharif I. Can the newest vital sign be used to assess health literacy in children and adolescents? Clinical Pediatrics (Phila). 2014 Feb;53(2):141-4. https://doi.org/10.1177/ 0009922813504025.

69. Friedman DB, Corwin SJ, Dominick GM, Rose ID. African American men's understanding and perceptions about prostate cancer: why multiple dimensions of health literacy are important in cancer communication. J Community Health. 2009;34:449-60.

70. Papen U, Walters S. Literacy, learning and health. London: National Research and Development Centre for Adult Literacy and Numeracy, Department for Innovation, Universities and Skills. 2008. http://dera.ioe.ac.uk/21966/1/doc_ 4323.pdf. Accessed 17 Jan 2016.

71. Papen U. Literacy, Learning and health-a social practices view of health literacy. Literacy and numeracy Studies. 2009;16(2-1):19.

72. Abel T, Hofmann K, Ackermann S, Bucher S, Sakarya S. (2015). Health literacy among young adults: a short survey tool for public health and health promotion research. Health Promot Int. 2015 Sep;30(3):725-35. https://doi. org/10.1093/heapro/dat096.

73. Easton P, Entwistle VA, Williams B. How the stigma of low literacy can impair patient-professional spoken interactions and affect health: insights from a qualitative investigation. BMC Health Serv Res. 2013;13:319. https:// doi.org/10.1186/1472-6963-13-319.

74. Paasche-Orlow MK, Wolf MS. the causal pathways linking health literacy to health outcomes. Am J Health Behav. 2007;31(Suppl 1):S19-26.
75. Osborne RH, Batterham RW, Elsworth GR, Hawkins M, Buchbinder R. The grounded psycho-metric development and initial validation of the health literacy questionnaire (HLQ). BMC Public Health. 2013;13(658)

76. Abel T, Sommerhalder K. Gesundheitskompetenz/Health Literacy: Das Konzept und seine Operationalisierung (Leitthema). Bundesgesundheitsblatt, Gesundheitsforschung, Gesundheitsschutz. 2015;58(9):923-9.

77. Bond $E$, Agnew S. How one county council is taking young people s views seriously. Education Journal Wales. 2013;(29):13-29.

78. James A, Prout A. Constructing and reconstructing childhood: contemporary issues in the socio-logical study of childhood. London: Routledge; 2015.

79. Macleod E, Woolford J, Hobbs L, Gross J, Hayne H, Patterson T. Interviews with children about their mental health problems: the congruence and validity of information that children report. Clinical child psychology and psychiatry. 2017;22(2):229-44. https://doi.org/10.1177/1359104516653642

80. McLaughlin H. Involving children and young people in policy, practice and research. Involving Children and Young People in Policy, Practice and Research. 2015. https://www.ncb.org.uk/sites/default/files/field/attachment/ listening_to_children_s_views_on_health_-_final_report_july_12.pdf. Accessed 14 May 2016.

81. Gibson F. Conducting focus groups with children and young people: strategies for success. J Res Nurs. 2007;12(5):473-83. https://doi.org/10.1177/ 1744987107079791

82. Gill $P$, Stewart $K$, Treasure $E$, Chadwick B. Conducting qualitative interviews with school children in dental research. Br Dent J. 2008;204(7):371-4. https://doi:10.1038/sj.bdj.2008.245

83. Peerson A, Saunders M. Health literacy revisited: what do we mean and why does it matter? Health Promot Int. 2009;24(3):285-96. https://doi.org/ 10.1093/heapro/dap014.

84. Nutbeam D. The evolving concept of health literacy. Soc Sci Med. 2008 Dec 67(12):2072-8. https://doi.org/10.1016/j.socscimed.2008.09.050.

85. Pleasant A, Rudd RE, O'Leary C, Paasche-Orlow MK, Allen MP, Alvarado-little $W$, et al. considerations for a new definition of health literacy. National Academy of Medicine. 2016; https://nam.edu/wp-content/uploads/2016/04/ Considerations-for-a-New-Definition-of-Health-Literacy.pdf

86. Baker DW. The meaning and the measure of health literacy. J Gen Intern Med. 2006 Aug;21(8):878-83. https://doi.org/10.1111/j.1525-1497. 2006.00540.x.

87. Tones K. Health Literacy: new wine in old bottles? Health Educ Res. 2002; 17(3):287-90. https://doi.org/10.1093/her/17.3.28.

88. Wills J. Health literacy: new packaging for health education or radical movement? International Journal of Public Health. 2009;54(1):3-4. https:// doi.org/10.1007/s00038-008-8141-7.

89. Sørensen K, Brand H. Health literacy lost in translations? Introducing the European health literacy glossary. Health Promot Int. 2013;29(4):634-44. https://doi.org/10.1093/heapro/dat013.

90. Malloy-Weir LJ, Charles C, Gafni A, Entwistle V. A review of health literacy: definitions, interpretations, and implications for policy initiatives. J Public Health Policy. 2016;37(3):334-52. https://doi.org/10.1057/jphp.2016.18

91. Bröder J, Okan O, Bauer U, Bruland D, Schlupp S, Bollweg TM, et al. health literacy in childhood and youth: a systematic review of definitions and models. BMC Public Health. 2017;17(1):361. https://dx.doi.org/10. 1186\%2Fs12889-017-4267-y

92. Mancuso JM. Assessment and measurement of health literacy: an integrative review of the literature. Nursing \& Health Sciences. 2009 Mar; 11(1):77-89. https://doi.org/10.1111/j.1442-2018.2008.00408.x.

93. McCormack L, Haun J, Sørensen K, Valerio M. (2013). Recommendations for advancing health literacy measurement. J Health Commun. 2013; 18(Suppl 1):9-14. 